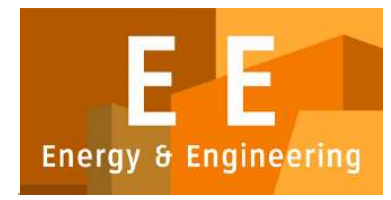

PAPER - OPEN ACCESS

\title{
Potensi Arsitektur Melayu Sebagai Warisan Budaya Di Sumatera Utara
}

\author{
Author $\quad$ : Imam Faisal Pane dkk., \\ DOI $\quad: 10.32734 /$ ee.v3i1.866 \\ Electronic ISSN $\quad: 2654-704 X$ \\ Print ISSN : $2654-7031$
}

Volume 3 Issue 1 - 2020 TALENTA Conference Series: Energy \& Engineering (EE)

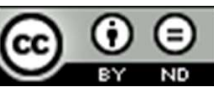

This work is licensed under a Creative Commons Attribution-NoDerivatives 4.0 International License.

Published under licence by TALENTA Publisher, Universitas Sumatera Utara

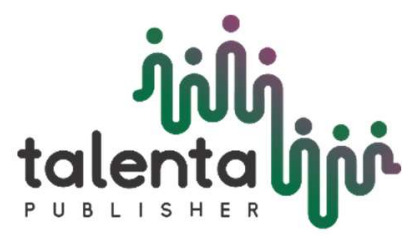




\title{
Potensi Arsitektur Melayu Sebagai Warisan Budaya Di Sumatera Utara
}

\author{
Potential Of Malitan Architecture As A Cultural Heritage In North Sumatera \\ (Studi Kasus : Masjid Al-Osmani Dan Masjid Raya Stabat) \\ Imam Faisal Pane ${ }^{\mathrm{a}}$, Sola Gratia Br Ginting ${ }^{\mathrm{b}}$, Yeny Salkina ${ }^{\mathrm{c}}$, Ainil Hafizhi Nasution ${ }^{\mathrm{d}}$ \\ ${ }^{1}$ Departemen Teknik Arsitektur, Fakultas Teknik, Universitas Sumatera Utara Medan 20155
}

Email : imamfpane@gmail.com, solagratia5014@gmail.com, salkinayen98@gmail.com, ainilhafizhi@gmail.com

\begin{abstract}
Abstrak
Suku Melayu adalah salah satu suku asli penduduk Sumatera Utara yang memiliki karakeristik Arsitekur Melayu yang berbeda di setiap daerahnya, yang dapat dilihat pada bentuk bangunan, ornamen dan makna pada elemen bangunan Melayu. Penelitian ini memfokuskan pada pengetahuan perbandingan karakteristik Arsitektur Melayu pada Masjid Al -Osmani dan Masjid Raya Stabat dan pengetahuan mengenai Kesultanan Melayu. Adapun tujuan dari penelitian ini adalah untuk memperkenalkan dan mengembalikan kejayaan Arsitektur Melayu serta mengetahui letak persamaan dan perbedaan kedua masjid. Penelitian ini dilakukan dengan metode kualitatif dengan mendeskripsikan secara deskiriptif bagaimana sejarahnya serta bentuk dari bagian-bagian masjid, struktur masjid, ornamen masjid kemudian melakukan perbandingan dari unsur-unsur kedua masjid tersebut untuk mendapatkan persamaan dan perbedaan yang terdapat pada kedua masjid. Data yang diperlukan dalam penelitian ini didapatkan melalui data primer dengan cara observasi, wawancara, rekam foto, sketsa ulang, serta mengumpulkan data skunder yang meliputi studi literatur tentang sejarah dan Arsitektur Melayu.
\end{abstract}

Kata Kunci: Kesultanan Melayu, Arsitektur Melayu, Masjid Al-Osmani, Masjid Raya Stabat ;

\section{Abstract}

The Malays are one of the original ethnic groups in North Sumatra who have different characteristics of Malay Architects in each area, which can be seen in the shape of buildings, ornaments and meanings in Malay building elements. This study focuses on the comparative knowledge of the characteristics of Malay Architecture in the Al-Ottoman Mosque and the Stabat Great Mosque and knowledge of the Malay Sultanate. The purpose of this research is to introduce and restore the glory of Malay Architecture and to find out the similarities and differences between the two mosques. This research was conducted with a qualitative method by describing descriptively how its history as well as the shape of the parts of the mosque, the structure of the mosque, the ornaments of the mosque then made a comparison of the elements of the two mosques to get similarities and differences found in the two mosques. The data needed in this study was obtained through primary data by observation, interview, photo recording, re-sketching, and secondary data collection which included literature studies on the history and architecture of Malay.

Keywords: Malay Sultanate, Malay Architecture, Al-Osmani Mosque, Stabat Great Mosque;

\section{Pendahuluan}

Suku melayu banyak bermukim si sebagian besar wilayah Malaysia, Sumatera, sekeliling pesisir Kalimantan, pesisir Timur Sumatera serta di pulau-pulau kecil lainnya (Kartini Ayu: 2014) Berbicara tentang bangunan berarti berbicara tentang arsitektur, Arsitektur membuat orang lebih mudah memahami tentang arti dari budaya maupun kebudayaan itu sendiri. Budaya yang sudah mulai luntur karena waktu, dapat disaksikan secara langsung melalui arsitektur yang berupa bangunan-bangunan lama peninggalan sejarah.

Budaya Melayu di tiap-tiap Kabupaten dan Kota memiliki ciri dan gaya tersendiri. Seperti simbol dan makna yang terdapat pada bangunan melayu. Keberadaan arsitektur Melayu dapat ditemui pada Masjid Al-Osmani di Kecamatan Medan Labuhan kota Medan dan Masjid Raya Stabat di Kecamatan Tanjung Pura Kabupaten Langkat. Kedua bangunan masjid ini memiliki karakteristik khas Melayu yang terlihat dari warna, bentuk bangunan yang hampir sama. Selain persamaan, terdapat perbedaan yang dapat dilihat dari 
segi arsitektur lokal yang diterapkan pada kedua bangunan, dimana pada Masjid Al-Osmani mengadopsi gaya arsitektur Melayu Deli dan Masjid Raya Stabat mengadopsi gaya arsitektur Melayu Langkat.

Dengan melakukan penelitian mengenai Masjid Al-Osmani dan Masjid Raya Stabat, kita dapat mengetahui bagaimana karakteristik arsitektur Melayu yang terdapat pada masing-masing bangunan, hal apa saja yang menarik mengenai kedua bangunan masjid tersebut, serta apa saja yang belum diketahui orang mengenai masjid tersebut. Kita juga dapat mengetahui bagaimana besar dan kuatnya pengaruh arsitektur Melayu bagi perkembangan kebudayaan di Sumatera Utara, dan apakah Arsitektur Melayu sebagai warisan budaya di Sumatera Utara dapat mempertahankan eksistensinya dan semakin dikenal pada saat ini.

\section{Tinjauan Pustaka}

\subsection{Suku Melayu}

Etnik melayu termasuk kedalam rumpun ras Austronesia. Kelompok etnik Melayu merupakan mayoritas kelompok yang tersebar di kawasan pesisir dan berasal dari kepulauan yang berpusat di Asia Tenggara, meliputi negara Malaysia, Indonesia, Thailand, Singapura, Kamboja dan lain-lain (Santy Mayda Batubara 2017). Sebelum Indonesia merdeka, Indonesia merupakan bagian kepulauan Nusantara. Beberapa daerah di Indonesia dikuasai oleh beberapa kerajaan yang dipimpin oleh sultan. Diantara kesultanan tersebut berpusat di daerah Sumatera Timur yang terdiri dari beberapa kerajaan Melayu seperti kerajaan Melayu Deli, Langkat, Batu Bara, Serdang, Asahan, Kualuh, Panai, Bilah dan Pinang Awan. Secara geografis, etnis Melayu di Indonesia terdapat di Riau, Kalimantan Barat, Palembang, Jambi, pesisir Timur Sumatera Utara dan Aceh Timur (Mailin 2017).

Masyarakat Melayu banyak mendiami daerah Pesisir Timur, salah satunya di Pulau sumatera, tepatnya di Sumatera Utara seperti daerah Langkat sampai ke Labuhan Batu. Sebagian masyarakat bermukim di sekitar Kotamadya Medan, Binjai, Tebing Tinggi dan Tanjung Balai. Sebagian lagi bermukim di Kabupaten Deli Serdang, Langkat, Asahan dan Labuhan Batu. Untuk membedakan dengan suku Melayu lain mereka lebih suka disebut sebagai orang Melayu Deli atau Melayu Langkat.

\subsection{Kesultanan Melayu}

Ada beberapa kesultanan Melayu di Indonesia khususnya di pulau Sumatra dan Kalimantan. Beberapa kesultanan Melayu yang terkenal diantaranya kesultanan Sri Wijaya, kesultanan Deli, kesultanan Langkat, kesultanan Asahan, kesultanan Johor Riau, dan kesultanan Sambas. Sumatra Utara memiliki beberapa kesultanan Melayu yaitu kesultanan Deli, kesultanan Langkat dan lain sebagainya.

Kesultanan Deli adalah salah satu kerajaan islam yang ada di Indonesia dan memiliki wilayah kekuasaan di Sumatra Utara. Berdirinya kesultaan Deli berkaitan dengan kedatangan Sultan Iskandar Muda dari Kesultanan Aceh. Pada tahun 1612 kesultanan Aceh Darussalam melakukan perluasan wilayah kesultanan ke Sumatra Utara dan menunjuk panglima bernama Tuanku Sri Paduka Gocah Pahlawan untuk memimpin pasukan Aceh dalam menguasai kota-kota di Sumatra Utara.

Kesultanan Langkat merupakan berusia paling tua di antara kesultanan-kesultanan Melayu di Sumatra Timur. Pada tahun 1568, salah satu petinggi Kesultanan Aru yaitu Dewa Shahdan yang berasal dari Tanah Karo berhasil menyelamatkan diri dari serangan yang diberikan Kesultanan Aceh lalu mendirikan sebuah kerajaan. Kerajaan inilah yang menjadi cikal-bakal Kesultanan Langkat modern.

\subsection{Arsitektur Melayu}

Menurut Effendi (2009), bangunan tradisional Melayu merupakan suatu bangunan yang utuh dan dapat dijadikan sebagai tempat tempat berketurunan, tempat bermusyawarah, kediaman keluarga dan tempat berlindung bagi siapa saja yang memerlukannya. Menurut Wahid \& Alamsyah (2013) Bangunan Melayu memiliki karateristik dari segi struktur bangunan yang terdiri dari atap, dinding, lantai, bubungan, pintu, jendela, tangga, tiang, warna dan ornamen.

Menurut Wahid dan Alamsyah (2013) Arsitektur Melayu Deli memiliki karakteristik dari segi struktur bangunan seperti atap umumnya memiliki bentuk seperti atap kajang, atap layar, atap limas dan atap lontik. Pada bubunganya berbentuk sederhana, panjang, tinggi serta curam. Untuk dinding bangunan biasanya terbuat dari papan, sedangkan lantainya memiliki ketinggian yang berbeda-beda. Pintu bangunan biasanya menghadap ke arah matahari terbit dan pada jendela bentuknya selalu memanjang keatas.

Arsitektur Melayu Langkat memiliki karakteristik dari segi struktur bangunan seperti atap yang sama dengan Melayu Deli, dinding yang terbuat dari kayu, pada warna biasanya menggunakan perpaduan warna terang dan gelap contohnya kuning, putih, coklat dan hitam. 


\subsection{Arsitektur Islam}

Arsitektur Islam banyak menggunakan bentuk geometris komplek, ornamen, hirarki bentuk dan ornamen yang memiliki makna mendalam. Arsitektur Islam mengandung nilai-nilai Islam yang mudah diterapkan dan dapat berbaur dengan teknologi modern saat ini.

Metode penggambaran seni ruang Islami dibagi menjadi lima kategori yaitu Hiasan penutup (overlay); Transigurasi bahan seperti pelengkung buntu, ceruk, serta elemen-elemen dinding lainya; Transfigurasi struktur yang berfungsi sebagai pengarah bangunan; Transfigurasi ruang tertutup yaitu menonjolkan abstraksi dengan menghilangkan kesan solid pada ruang; dan Ambiguitas fungsi yaitu penggunaan ruang tidak hanya satu tujuan.

Ada 4 langgam arsitektur islam yang terkenal, yaitu langgam ottoman berpusat di Turki dan Mesir, langgam mugal yang berpusat di India, langgam Persia yang berpusat di semenanjung Arab dan Iran serta langgam Moorish yang berpusat di Spanyol. Langgam yang paling banyak di adopsi pada arsitektur melayu adalah langgam Moorish. Ciri khas langgam Moorish dapat dilihat pada bukaan jendela yang melengkung di bagian atasnya yang tidak pernah ditemukan pada bangunan Melayu asli.

Simbol Rukun Islam sering diterapkan dalam jumlah anak tangga maknanya adalah jumlah anak tangga tujuh dapat melambangkan tujuh lapis langit, jumlah anak tangga enam dapat melambangkan rukun iman, jumlah anak tangga lima dapat melambangkan rukun Islam serta jumlah anak tangga empat dapat melambangkan empat sahabat nabi (Abu Bakar, Umar, Usman, dan Ali).

\subsection{Arsitektur Masjid}

Masjid merupakan tempat ibadah umat muslim, tempat sujud, bermusyawarah dan kegiatan-kegiatan lainya yang merujuk kepada hal-hal positif, di Indonesia sendiri Masjid sering disebut dengan Musholla, Langgar atau Surau. Menurut Frehman (1997) dalam penelitian Sri Gunana (2018 "Refresentasi Arsitektur Islam dikawasan pusat kota Medan (Studi kasus : Masjid gang bengkok dan masjid Al - Osmani)". Bangunan masjid terdiri dari bagian-bagian bangunan antara lain kubah, menara, taman, aula sholat, mihrab, dan mimbar.

\section{Metode Penelitian}

Penelitian ini menggunakan metode kualitatif deskriptif dilakukan dengan cara pengumpulan data yang meliputi data primer yang berupa observaasi, wawancara dan sketsa ulang, kemudian dengan data sekunder yaitu berupa studi literatur. Data-data yang sudah terkumpul akan dianalisis, setelah data dianalisis selanjutnya diambil kesimpilan hasil dari penelitian.

\section{Hasil Penelitian}

\subsection{Perbandingan karakteristik dari segi struktur, ornamen dan bagian bangunan Masjid Al-Osmani dan Masjid Raya Stabat}

\subsubsection{Struktur bangunan}

Menurut Wahid dan Alamsyah (2013) Arsitektur Melayu Deli memiliki karakteristik dari segi struktur bangunan, yaitu:

Pintu Masjid Al-Osmani memiliki 2 jenis pintu yang terbuat dari kayu dengan menggunakan warna dari ciri khas Melayu Deli yaitu kuning dan hijau. Pintu utama berukuran 180 x $270 \mathrm{~cm}$ dan pintu kedua berukuran 150 x $230 \mathrm{~cm}$. Pada daun pintu terdapat ornamen geometri yang merupakan khas Arsitektur China.

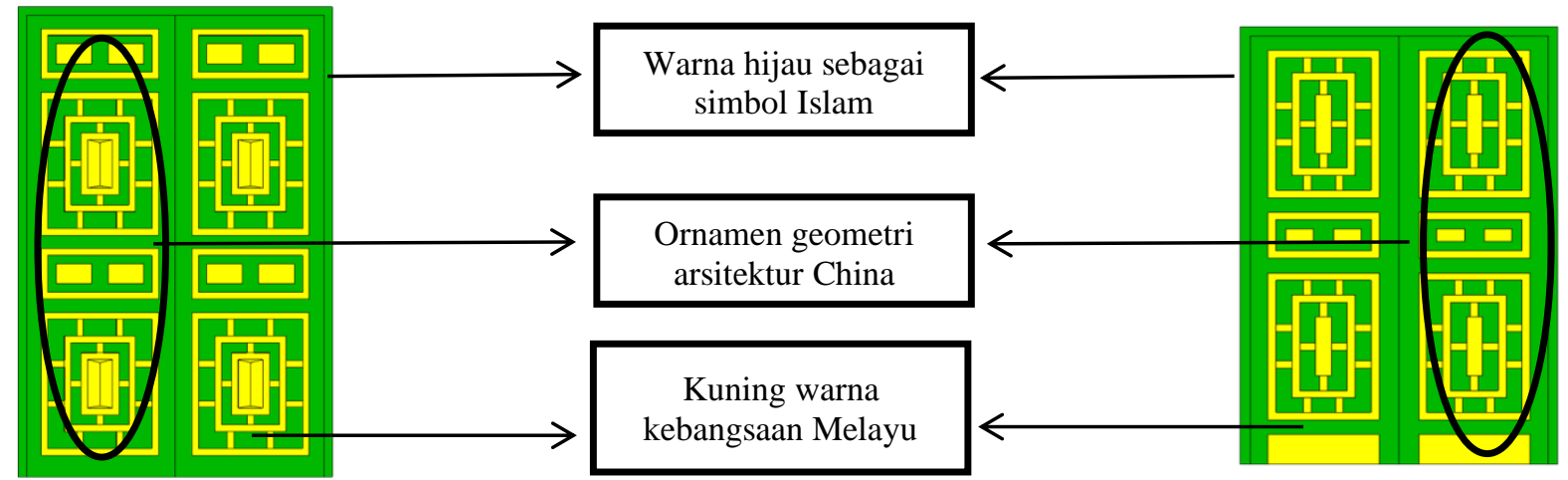

Gambar 1. Pintu Utama dan Kedua Masjid Al - Osmani 
Pintu Masjid Raya Stabat terbuat dari kayu dengan menggunakan warna ciri khas Melayu Langkat yaitu kuning dan hijau, berukuran 183 x $276 \mathrm{~cm}$. Pada daun pintu terdapat ornamen geometri yang merupakan khas Arsitektur China.

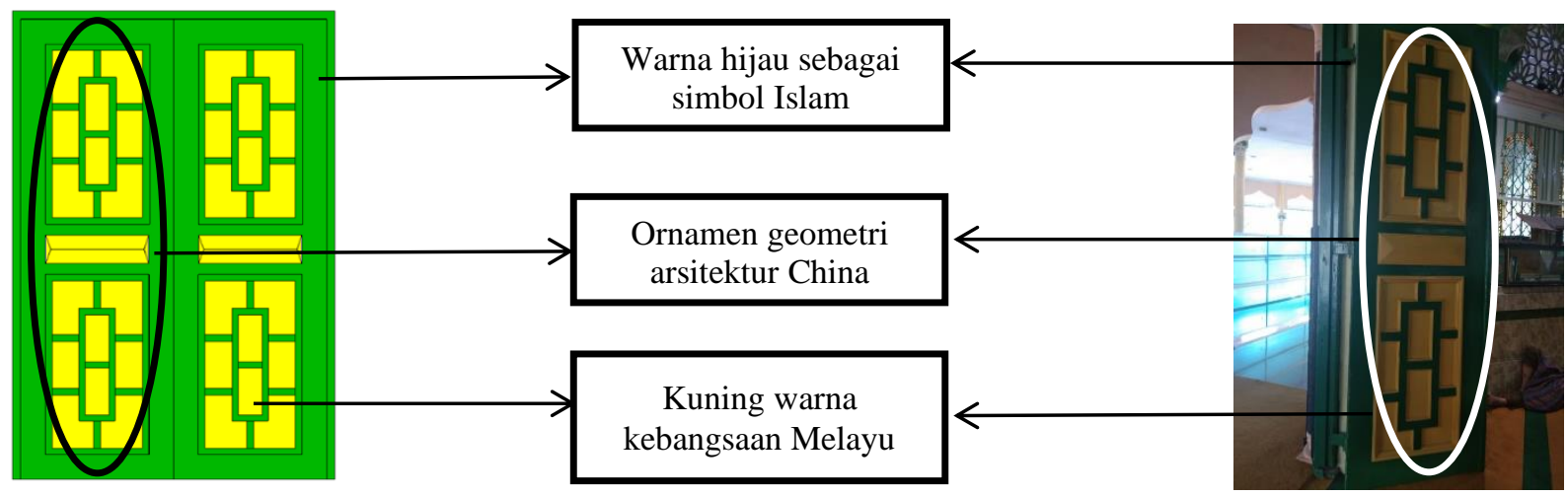

Gambar 2. Pintu Masjid Raya Stabat

\section{Jendela}

Jendela Masjid Al-Osmani berukuran 213 x $130 \mathrm{~cm}$, menggunakan warna hijau dan kuning. Jika dilihat dari bentuknya, jendela tersebut mengadopsi langgam Moorish terlihat dari lengkungan dibagian atas jendela.

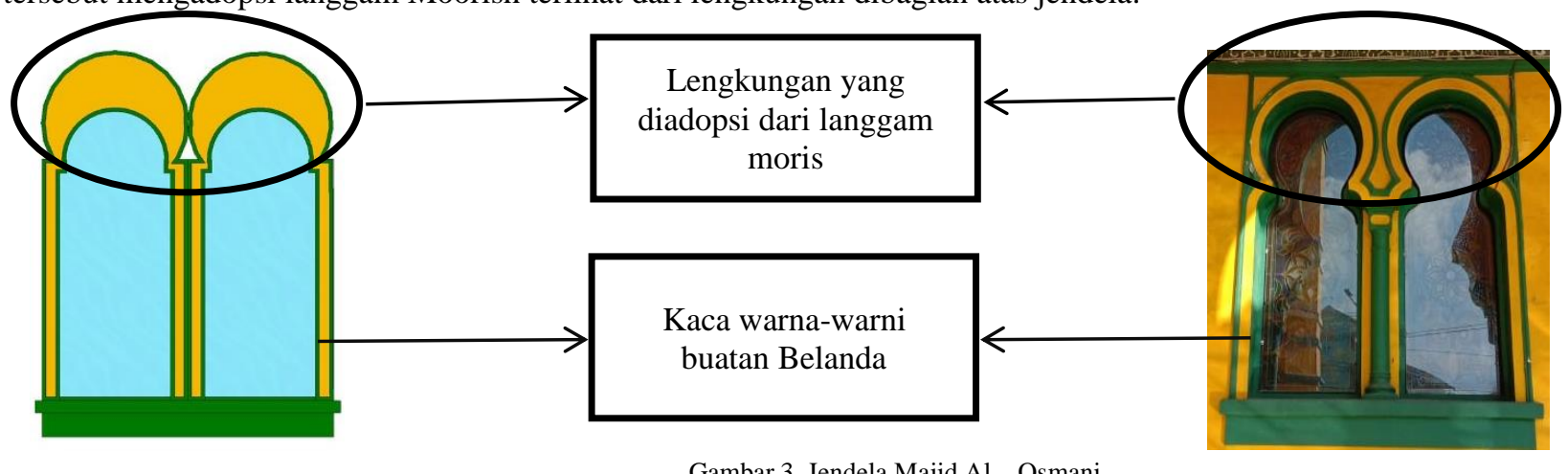

Jendela Masjid Raya Stabat berukuran 217 x $174 \mathrm{~cm}$, menggunakan warna putih dan hijau yang merupakan ciri khas Melayu Langkat. Jendela tersebut mengadopsi langgam Moorish terlihat dari lengkungan dibagian atas jendela.

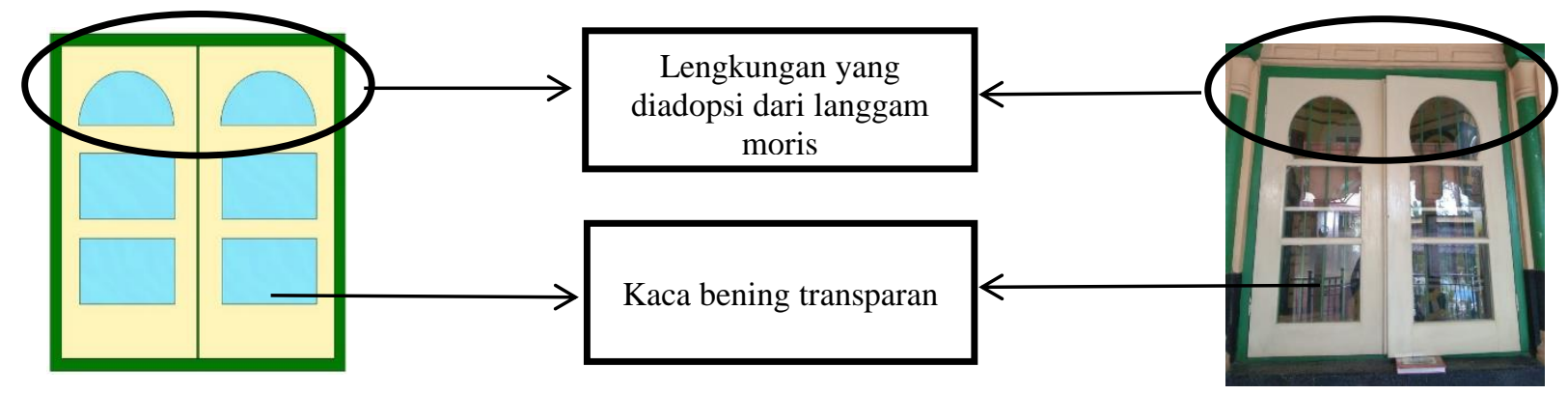

Gambar 4. Jendela Masjid Raya Stabat

\section{Tangga dan Lantai}

Pada masjid Al - Osmani terdapat 3 buah anak tangga yang memiliki makna tersendiri dalam islam misalnya dalam pembacaan dzikir sebanyak tiga kali baik dalam sholat maupun tidak. Tangga tersebut menggunakan material keramik berukuran $30 \mathrm{x} 30 \mathrm{~cm}$ berwarna putih. Sebelum melakukan renovasi, material yang digunakan pada lantai adalah lantai tegel. 

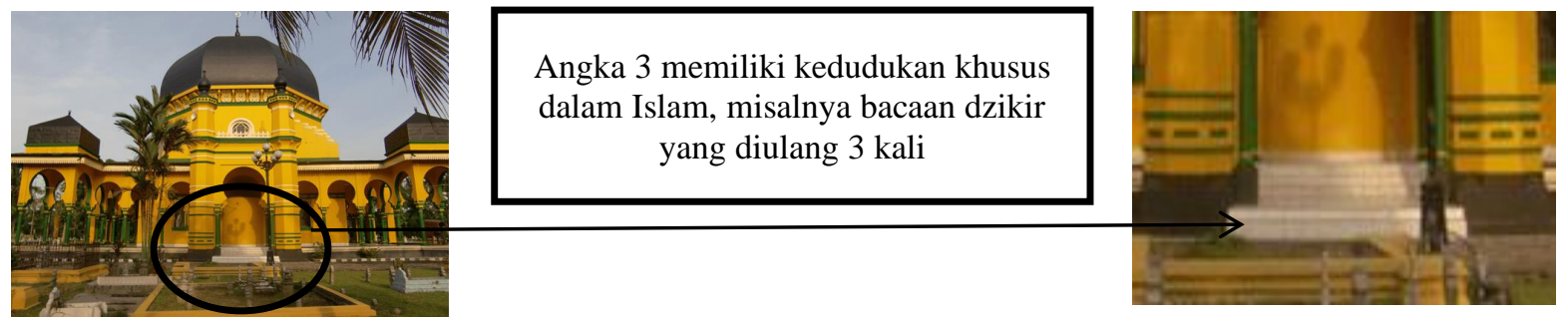

Gambar 5. Tangga dan Material Lantai Masjid Al - Osmani

Pada Masjid Raya Stabat terdapat 5 anak tangga yang merupakan jumlah rukun Islam.Pada bagian tangga menggunakan material keramik berukuran $60 \times 60 \mathrm{~cm}$ berwarna putih. Pada bagian dalam (aula shalat) material penutup lantai yang digunakan yaitu marmer berwarna hitam.

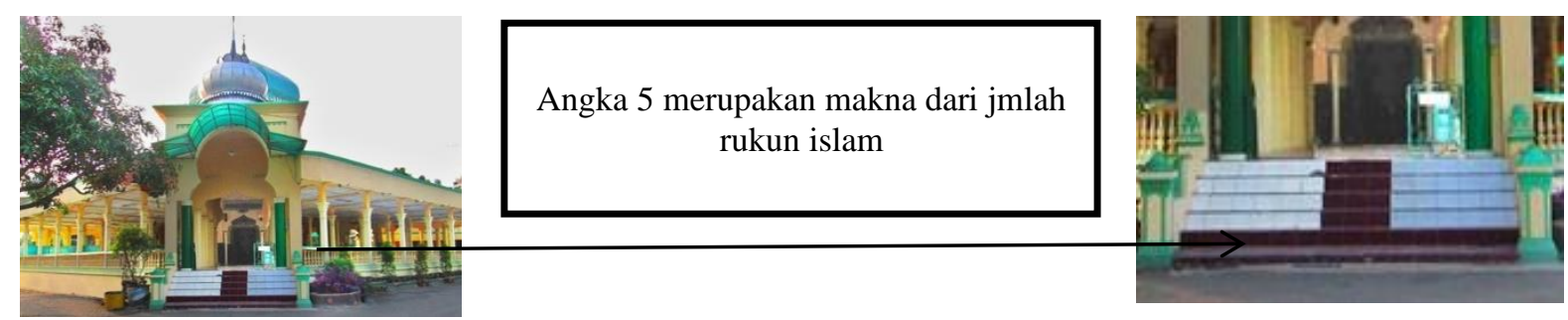

Gambar 6. Tangga dan Material Lantai Masjid Raya Stabat

\section{Tiang}

Tiang Masjid Al-Osmani berbentuk silindris berdiameter $20 \mathrm{~cm}$ dan tinggi $2 \mathrm{~m}$ dengan landasan tapak berbentuk persegi berukuran 40 x $40 \mathrm{~cm}$, menggunakan warna kuning dan hijau. Jika dilihat dari bentuk tiang tersebut mengadopsi langgam Persia.

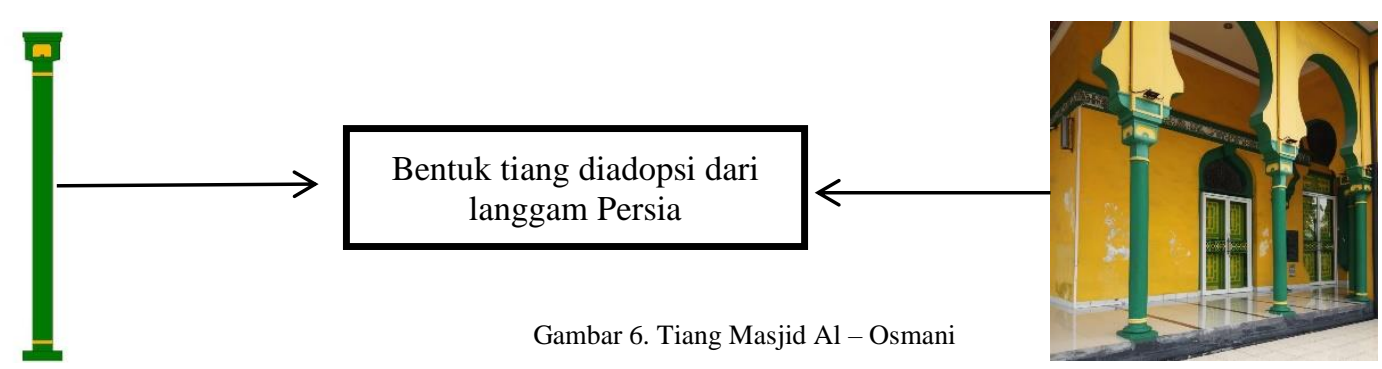

Tiang Masjid Raya Stabat berbentuk silindris berdiameter $20 \mathrm{~cm}$, berwarna kuning, putih dan hijau. Pada bagian kepala tiang berbentuk kelopak bunga dimana bunga merupakan ciri khas dari Melayu dimana memiliki makna keindahan, jika dilihat dari bentuk tiang tersebut mengadopsi langgam Persia.

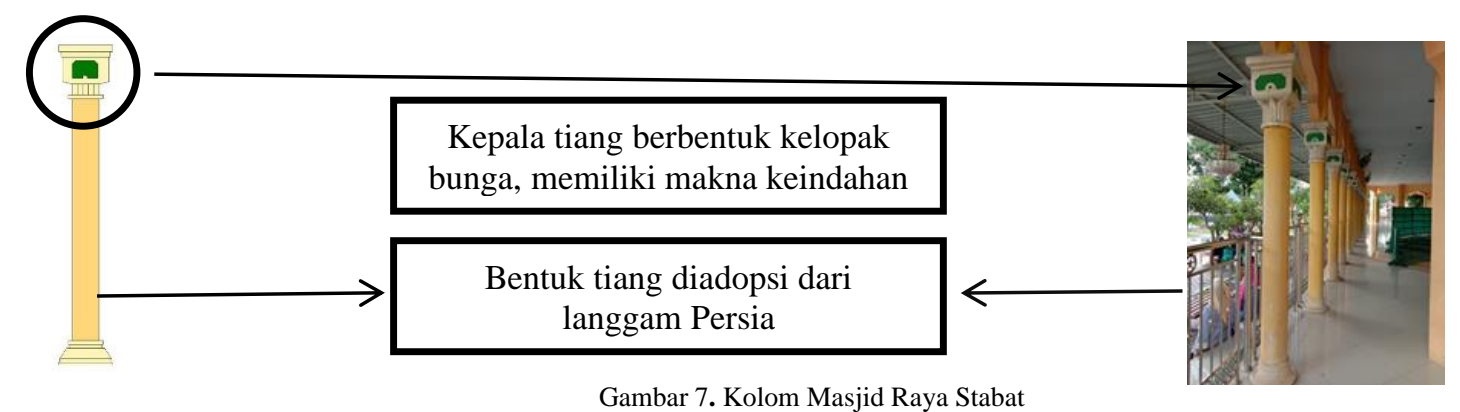

Gambar 7. Kolom Masjid Raya Stabat 


\section{Ornamen}

Ornamen Masjid Al-Osmani beraneka ragam, pada bagian lisplang menggunakan ornamen lebah bergantung, menurut hasil wawancara dengan ketua BKM yaitu pak Ahmad Faruni, lebah bergantung diambil dari filosofi lebah, lebah bagi umat Islam cukup berarti, tidak ada lebah yang tidak bermanfaat, maka melayu ini dia hidup ditengah masyarakat maunya bermanfaat untuk masyarakat. Kemudian pada bagian atap datar menggunakan ornamen bunga tanjung, yang berarti keindahan. Selain itu terdapat ornamen tumbuhan dibagian atas atas jendela, dari hasil wawancara dengan pak Ahmad Faruni bunga merupakan lambang kedamaian dan Melayu Deli suka dengan ketentraman. Dan pada bagian plafond kubah mengambil ornamen pucuk rebung yang maknanya kebahagian dan ornamen Itik Sekawan yang memiliki makna kerukunan.
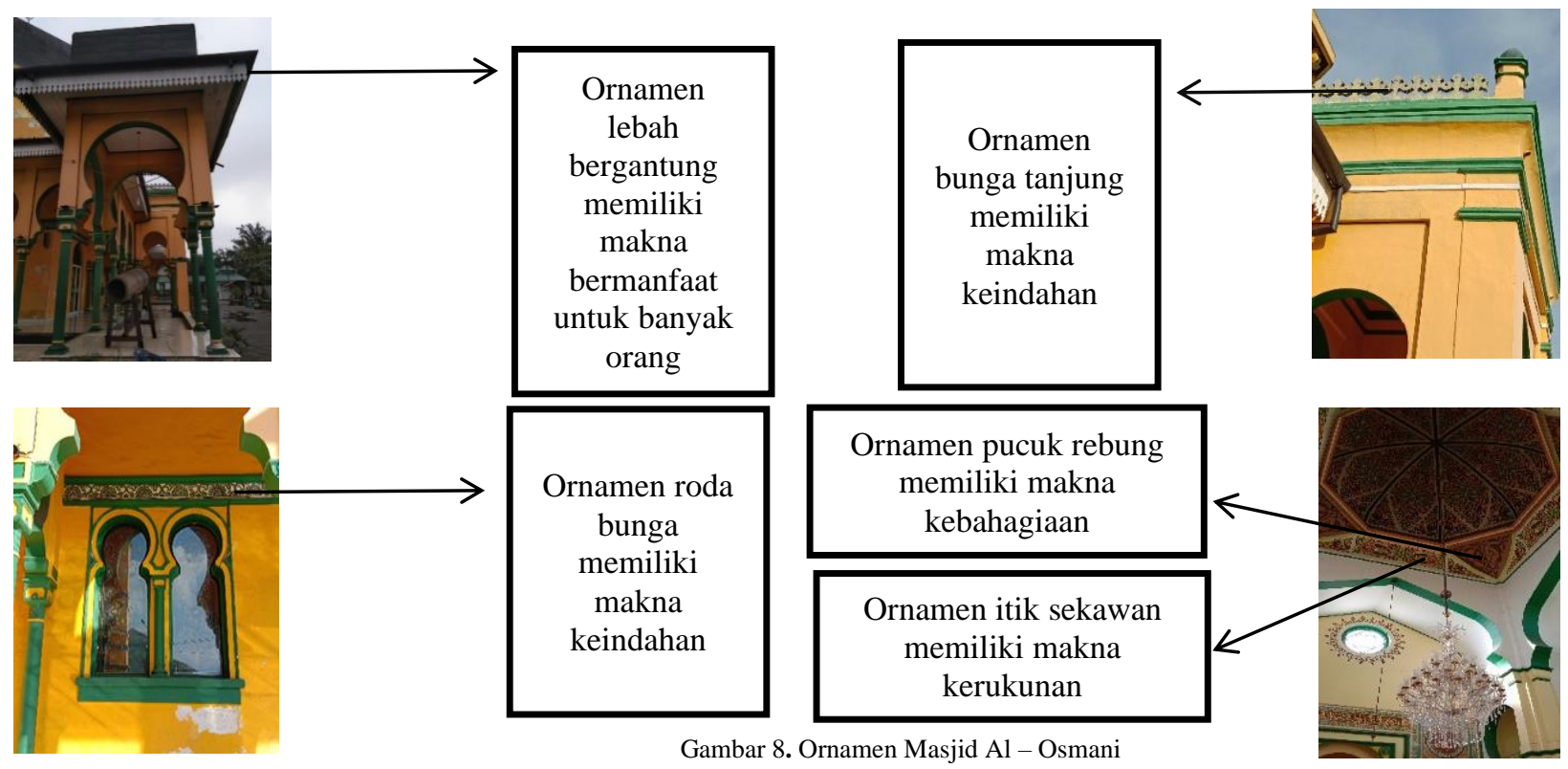

Ornamen Masjid Raya Stabat beraneka ragam, pada bagian atap menggunakan ornamen bunga Tanjung yang memiliki makna kedamaian, pada bagian menara dan kubah atap memiliki ornamen lebah bergantung yang memiliki banyak manfaat dan bagian kubah utama terdapat ornamen pucuk rebung yang memiliki makna kebahagian.
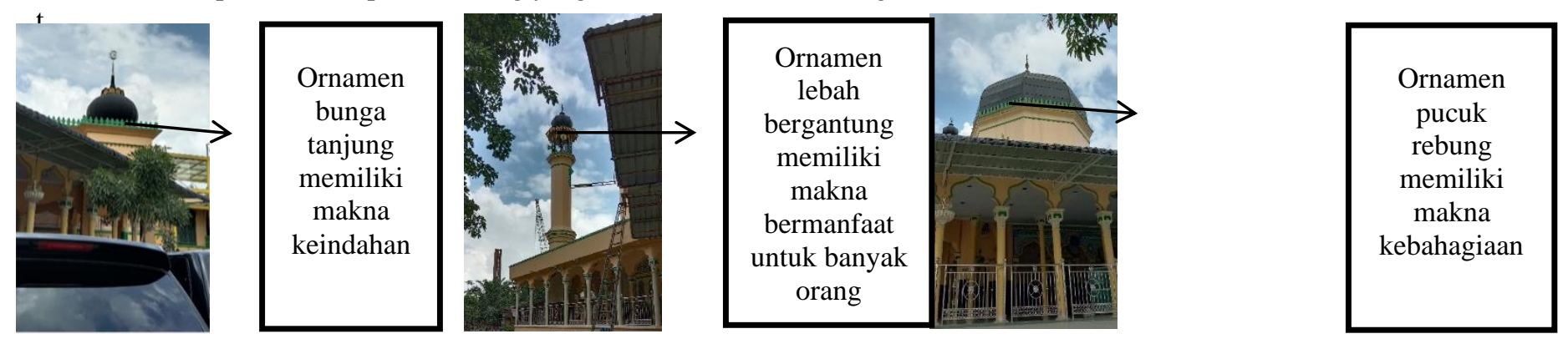

Gambar 9. Ornamen Masjid Raya Stabat

\section{Kubah}

Kubah utama Masjid Al-Osmani berbentuk persegi delapan mengadopsi gaya Arsitektur Spanyol, bentuk segi delapan diambil dari simbol Islam dimana 8 merupakan jumlah sifat wajib dan mustahil Nabi Muhammad SAW, pada anak kubah menggunakan kubah biara (cloister vault) yang merupakan kubah dengan dasar persegi, bentuk tersebut diambil dari simbol Islam yaitu sifat Nabi Muhammad SAW. 

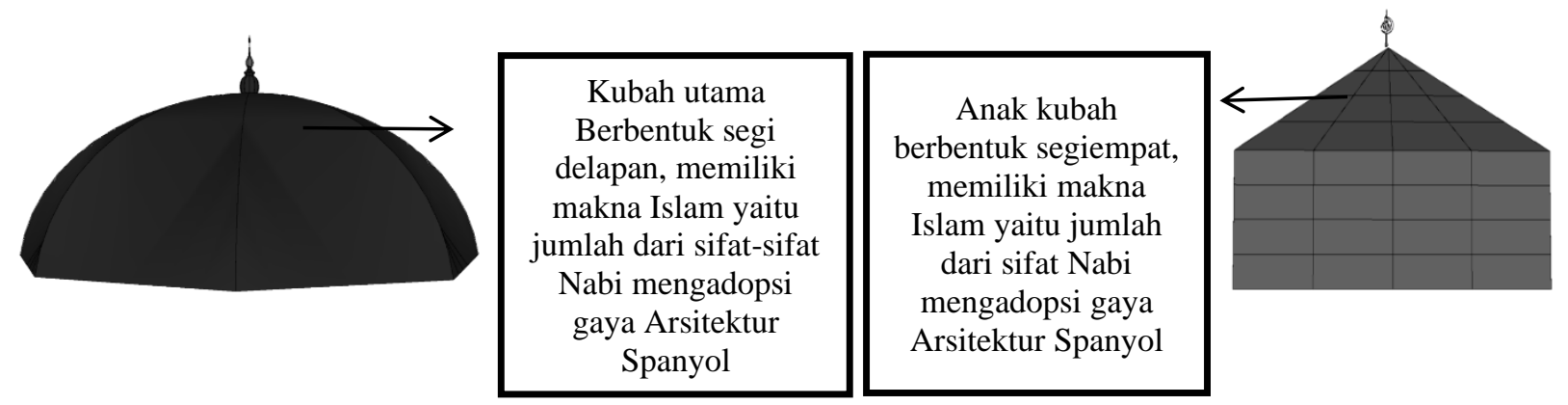

Gambar 10. Kubah Utama dan Kubah Serambi Masjid Al - Osmani

Kubah utama Masjid Raya Stabat juga berbentuk segi delapan mengadopsi gaya Arsitaketur Spanyol dan memiliki simbol Islam, yaitu sifat wajib dan mustahil Nabi Muhammad SAW. Pada anak kubah berbentuk lingkaran, jika dilihat dari bentukannya mengambil gaya Arsitektur Arab.

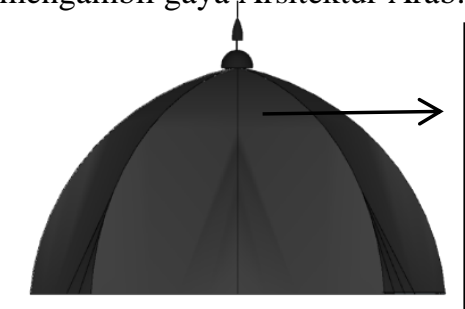

Kubah utama Berbentuk segi delapan, memiliki makna Islam yaitu jumlah dari sifat-sifat Nabi mengadopsi gaya Arsitektur Spanyol
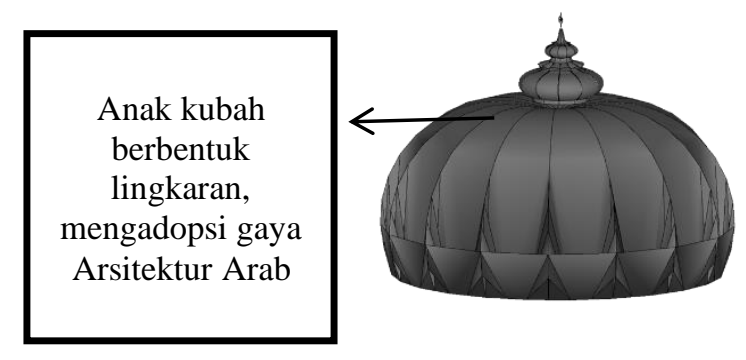

Gambar 11. Kubah Utama dan Kubah Serambi Masjid Raya Stabat

\section{Menara}

Menara Masjid Al-Osmani berada di depan, berbentuk segi delapan berukuran 147 x 147cm, landasan tapak menara berebentuk persegi berukuran 40 x 40, warna yang digunakan yaitu hijau, kuning dan putih yang merupakan ciri khas dari warna Melayu, menara masjid tersebut berbeda dengan menara masjid lainnya, menurut hasil wawancara dengan Pak Daeng selaku imam besar di Masjid Al-Osmani, menara dibuat dengan bentuk tersebut (lihat Gambar 12) karena pada zaman dulu ilmu pengetahuan masyarakat masih minim sehingga terbangun menara seperti masjid tersebut.

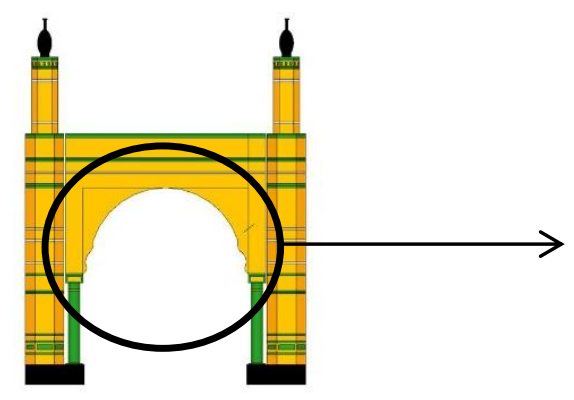

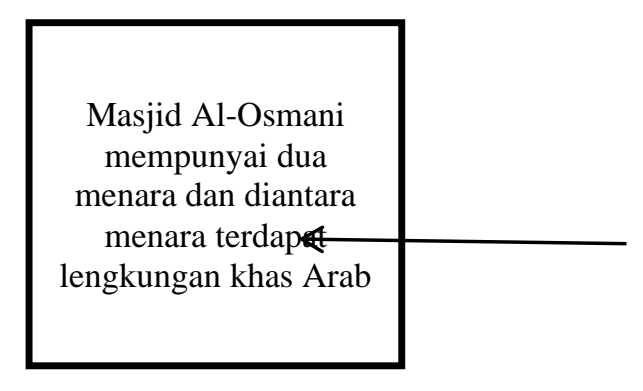

Gambar 12. Menara Masjid Al - Osmani

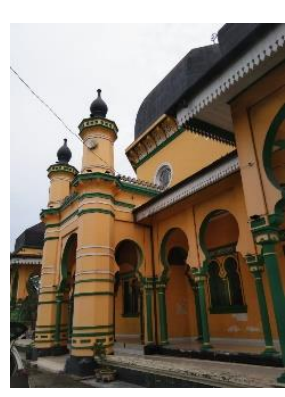

Menara Masjid Raya Stabat berada dibelakang masjid berbentuk segi lima, yang memiliki simbol Islam yaitu jumlah dari rukun Islam, ukuran setiap sisi menara $82 \mathrm{~cm}$ dengan warna hijau dan kuning.

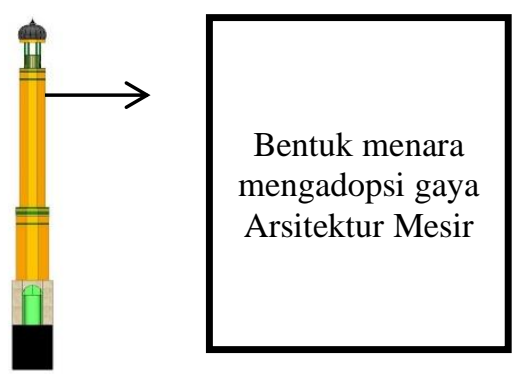

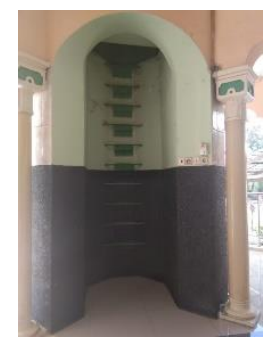




\section{Taman}

Taman pada Masjid Al - Osmani tidak berpola hypostyle yang artinya tidak terdapat didalam bangunan. Menurut Bapak Ahmad Faruni taman pada Masjid Al - Osmani merupakan tempat berkumpul Sultan Deli dan para kerabat ketika meunjungi Masjid Al Osmani. Taman ini merupakan penghubung antara bangunan dengan alam dan merupakan taman terbuka yang terletak di luar bangunan.

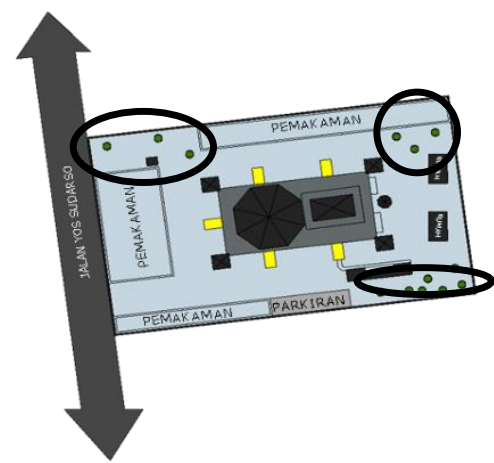

Gambar 14. Taman Masjid Al - Osmani

Taman yang terdapat pada Masjid Raya Stabat berpola hypostyle dan bukan hypostlye karena terdapat dibagian dalam dan luar bangunan. Taman ini berupa halaman terbuka namun sebagian besar ditutupi dengan perkerasan sehingga dijadikan parkiran. Selain itu terdapat beberapa kursi dan meja taman yang disusun disisi masjid sebagai tempat duduk dan bersantai.

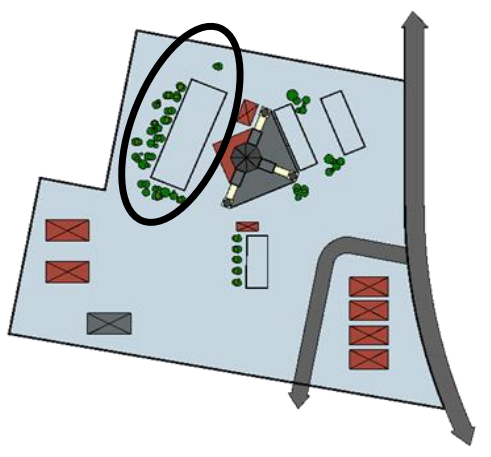

Gambar 15. Taman Masjid Raya Stabat

\section{Aula Shalat}

Pada Masjid Al - Osmani memiliki aula sholat berbentuk persgi panjang dengan ukuran 17m x 14,5m. Untuk mencapai aula sholat dengan menggunakan tangga yang terdapat pada penampil di serambi, tangga merupakan salah satu karakteristik dari arsitektur melayu. Pada aula sholat ini terdapat tiga buah pintu dan jendela pada sisi kiri dan kanan mihrab. Warna yang digunakan adalah kuning dan hijau serta menggunakan keramik pada dinding bagian bawah.
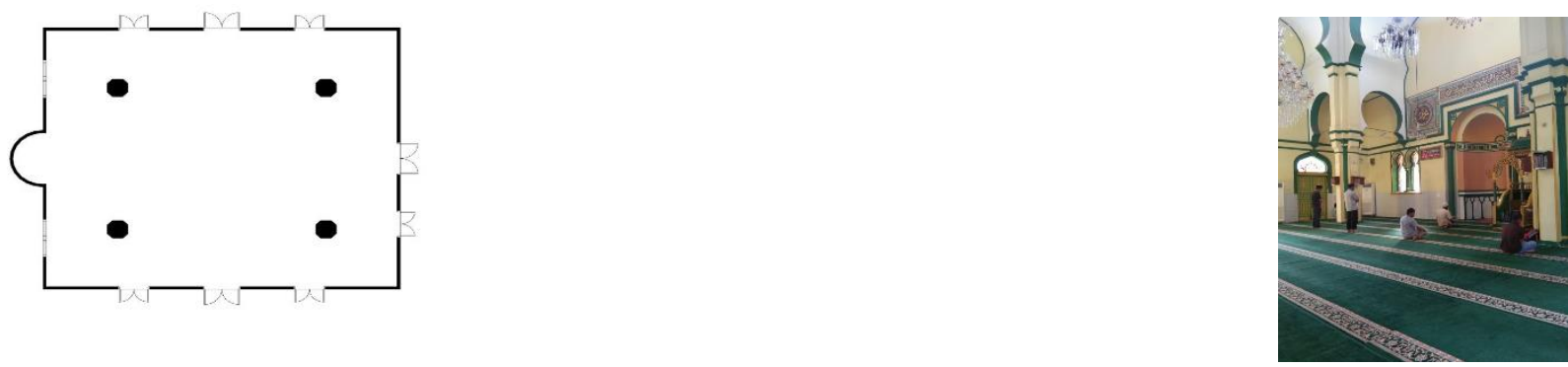

Gambar 16. Aula Sholat Masjid Al - Osmani

Pada Masjid Raya Stabat memiliki aula sholat berbentuk segi delapan dengan ukuran setiap sisinya 4,3 m .pada aula sholat ini terdapat tiga buah pintu dan juga jendela pada setiap sisi dindingnya. Warna yang digunakan adalah kuning, dan hijau serta menggunakan keramik pada dinding bagian bawah. 

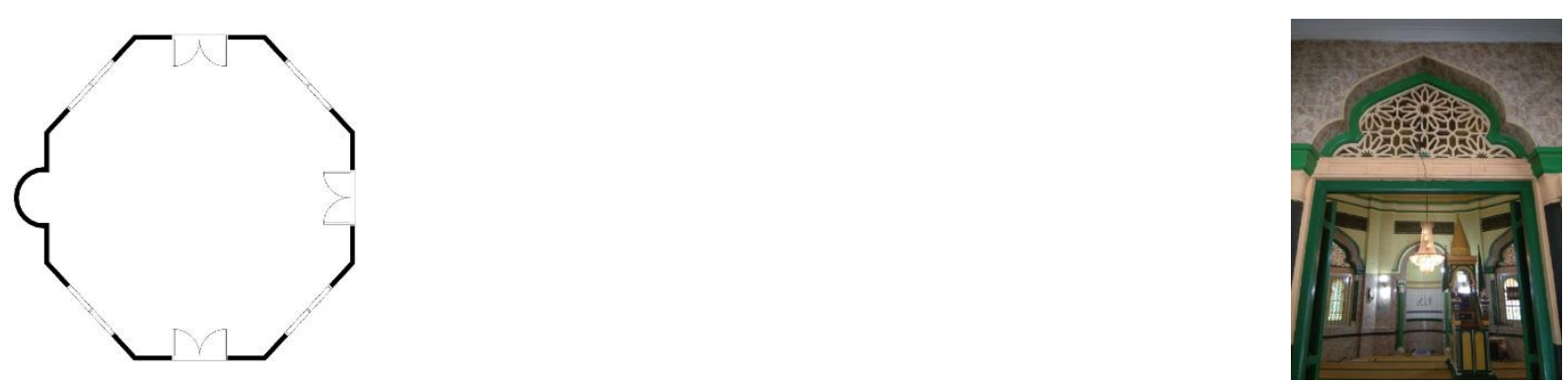

Gambar 17.Aula Sholat Masjid Raya Staba

\section{Mihrab}

Mihrab pada masjid Al - Osmani berada di bagian tengah aula sholat, pada dinding mihrab terdapat lis dinding berwarna hijau serta warna dasar kuning keemasan pada mihrab, terdapat ornamen geometri yang diberi warna hijau serta penerapan keramik pada dinding bagian bawah mihrab. Pada sisi kiri dan kanan mihrab terdapat kolom dengan diameter kecil berwarna hijau.
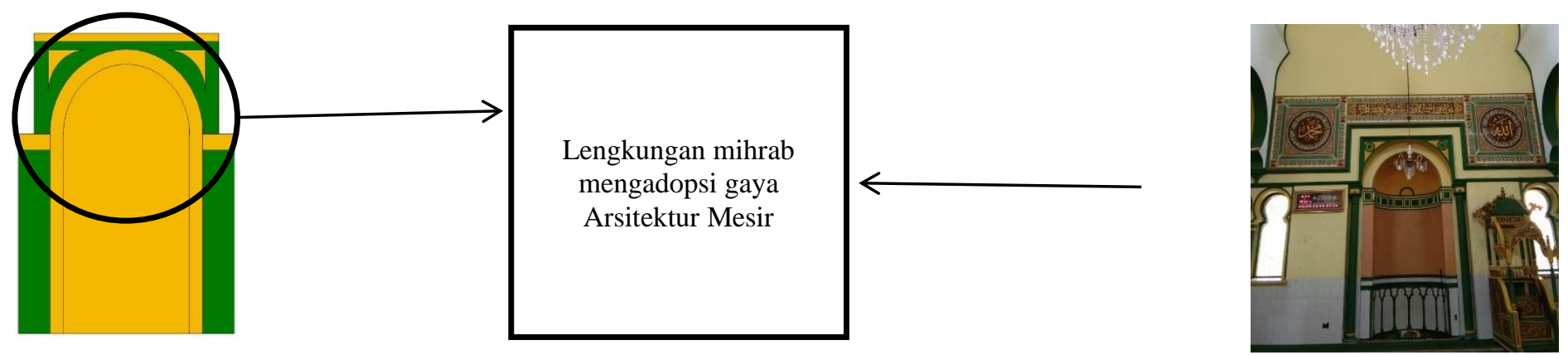

Gambar 18. Mihrab Masjid Al - Osmani

Mihrab pada masjid Raya Stabat terdapat di tengah aula sholat berdinding keramik putih dan keramik bermotif warna coklat serta dan pada dinding bagian atas mihrab yang tidak menggunakan keramik di beri warna kuning. Bagian sisi kiri dan kanan mihrab terdapat kolom berdiameter kecil berwarna hijau.

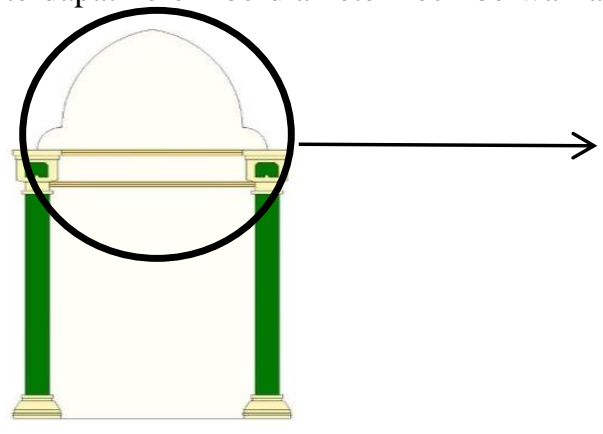

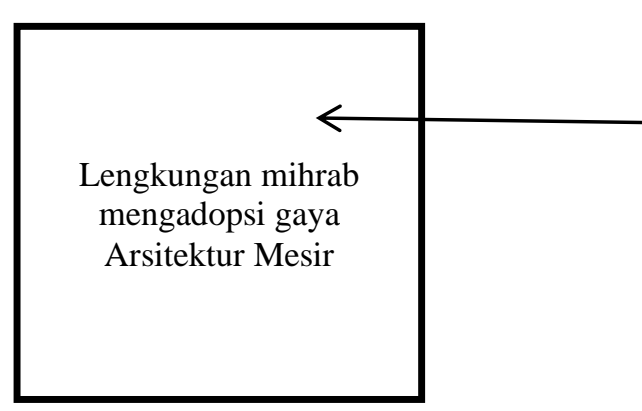

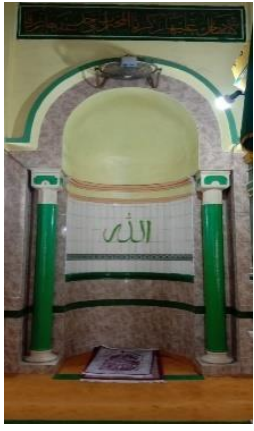

Gambar 19. Mihrab Masjid Raya Stabat

\section{Mimbar}

Mimbar pada Masjid Al - Osmani terletak pada sisi sebelah kanan mihrab dengan ukuran $140 \mathrm{~cm}$ x $80 \mathrm{~cm}$ dengan ketinggian $2,7 \mathrm{~m}$. Terdapat dua buah anak tangga sehingga membentuk panggung. Mimbar ini terbuat dari kayu diberi cat berwarna kuning dan hijau serta terdapat ornamen floral berupa "kaluk pakis" dan "bunga kundur". Atap mimbar berbentuk trapesium berwarna hijau. 


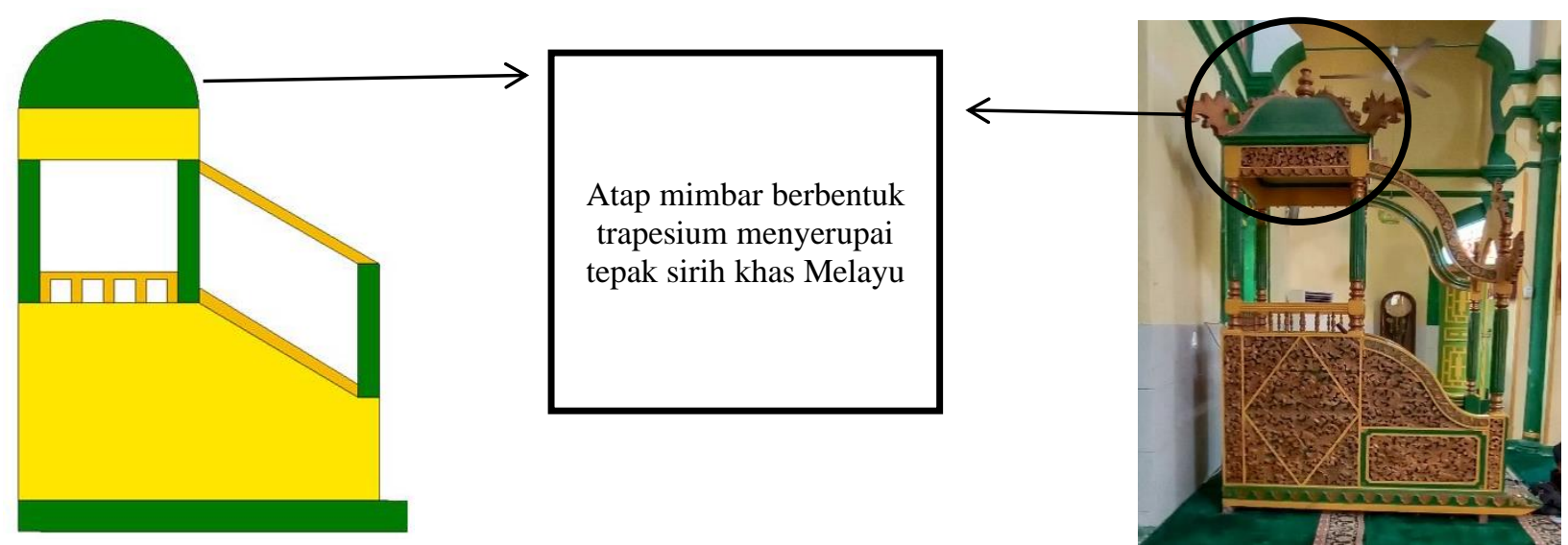

Gambar 20. Mimbar Masjid Al-Osmani

Mimbar pada Masjid Raya Stabat terletak terletak di sebelah kanan mihrab berukuran $228 \mathrm{~cm}$ x $87 \mathrm{~cm}$ dengan ketinggian $2 \mathrm{~m}$. Terdapat lima buah anak tangga yang menggambarkan rukun islam. Mimbar ini terbuat dari kayu yang diberi warna hijau, kuning dan putih di beberapa lis mimbar. Pada sisi kiri dan kanan mimbar diberi kolom berdiameter kecil dengan kubah pada bagian ujungnya. Atap mimbar berbentuk kerucut berwarna kuning.

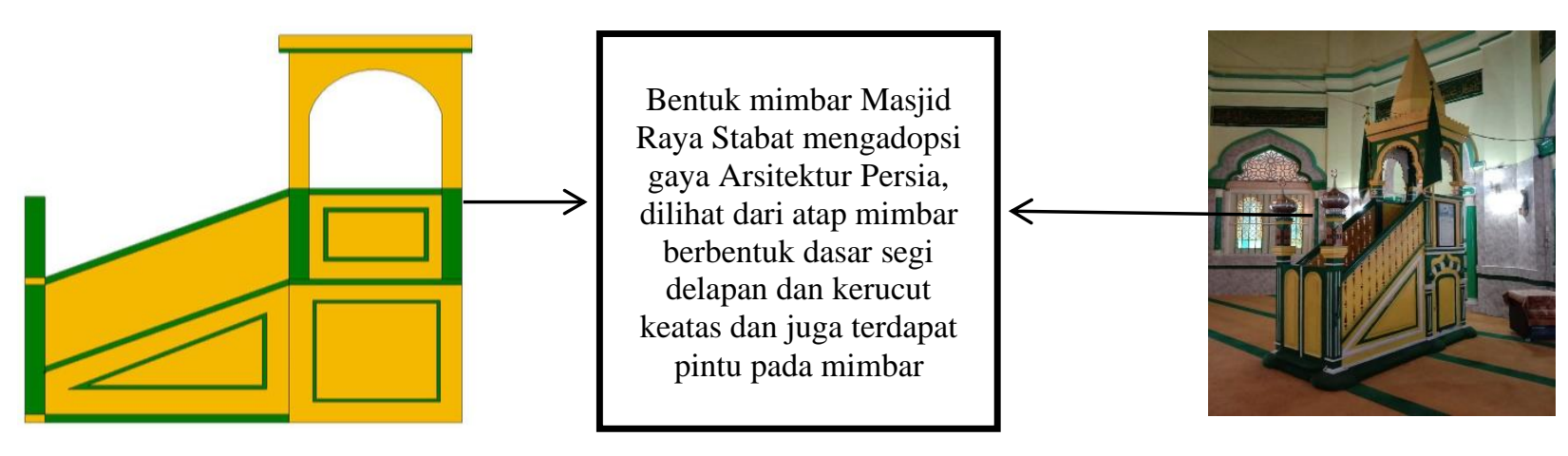

Gambar 21. Mimbar Masjid Raya Stabat

\section{Potensi Arsitektur Melayu untuk Mengembalikan Kejayaan agar di Kenal oleh Banyak Orang}

Pada umumnya Arsitektur Melayu berbentuk rumah panggung yang memanjang, bentuk panggung ini beradaptasi dengan kawasan tropis kepulauan dengan hutan yang lebat dan berawa-rawa. Selain itu bentuk panggung juga diperlukan untuk mengatasi resiko hewan buas dipesisir dan rimba serta mengatasi resiko banjir. Bentuk memanjang pada arsitektur Melayu diperlukan untuk perluasan agar seluruh keluarga dapat tinggal dalam satu rumah yang memanjang dan untuk mengatasi kebutuhan sosial. Dari segi atap bangunan Melayu memiliki atap yang berlapis dengan tritisan lebar, tiang bulat, tanpa loteng dengan kayu sebagai bahan utama bangunan. 

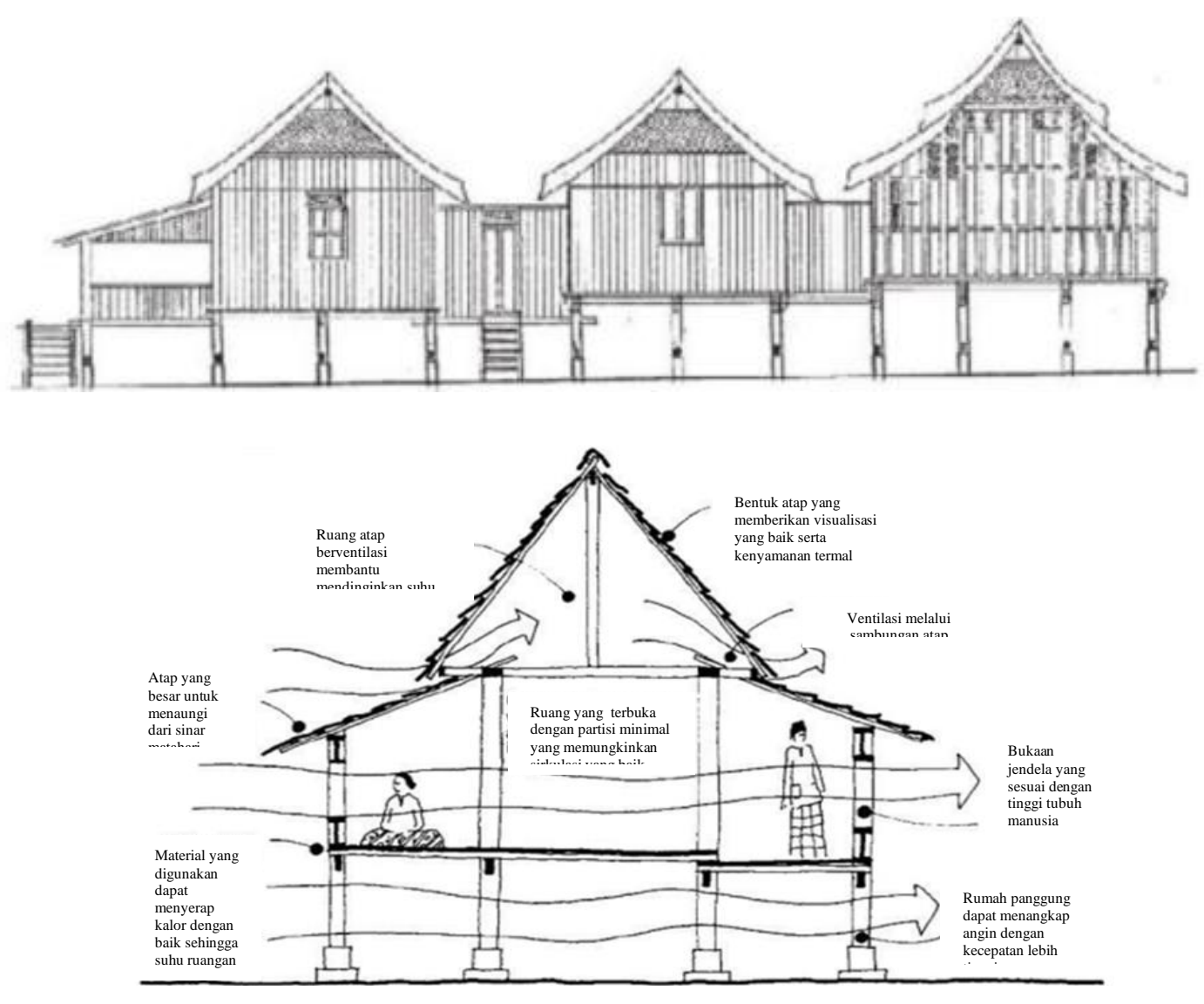

(Sumber : Wikipedia, 2016)

Gambar 21. Rumah Melayu

Dari analisa diatas didapatkan beberapa keunggulan bangunan dengan Arsitektur Melayu seperti berbentuk rumah panggung dengan atap tinggi dan bukaan yang lebar sehingga memungkinkan sirkulasi udara yang baik. Rumah panggung memliki kegunaan untuk tempat mengalirnya udara dengan lebih leluasa. Atap tinggi dengan ruang diantaranya dapat memperlancar sirkulasi udara dan dapat menjaga suhu ruangan pada bangunan agar tetap terasa sejuk. Keunggulan ini dapat diterapkan dalam bangunan modern masa kini.

Pada kedua bangunan masjid (Masjid Al-Osmani dan Masjid Raya Stabat) telah dijabarkan beberapa persamaan dan perbedaan pada kedua masjid tersebut. Persamaan yang paling mencolok yaitu penggunaan warna hijau dan kuning yang dominan pada kedua masjid serta penggunaan ornamen-ornamen baik itu ornamen tumbuhan (roda bunga, bunga tanjung, pucuk rebung), hewan (lebah bergantung, itik sekawan), dan geometris yang merupakan ciri khas arsitektur melayu Deli dan Langkat. Kedua persamaan tersebut (warna dan ornamen) merupakan kekuatan dari arsitektur melayu.

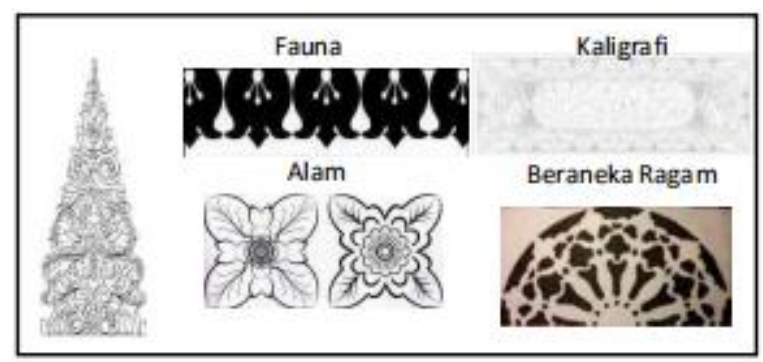

(Sumber:Ayu Kartini, 2014)

Gambar 23. Ornamen Arsitektur Melayu

Dengan menggabungkan keunggulan dari kedua masjid dengan Arsitektur Melayu serta keunggulan dari bangunan tradisional melayu maka akan tercipta sebuah inovasi yang berpotensi untuk menunjukkan eksistensi Arsitektur Melayu. Penerapan ornamen dan warna khas melayu Deli dan Langkat dipadu dengan penggunaan atap bangunan yang tinggi untuk sistem sirkulasi yang baik dapat 
menjadi kekuatan tersendiri untuk diterapkan pada bangunan modern masa kini. Bangunan modern dengan sentuhan ornamen maupun warna khas melayu tentu akan menjadi sebuah keunggulan, yang akan mengangkat kembali eksistensi Arsitektur Melayu. Bukan hanya mengembalikan eksistensinya, namun hal ini dapat menjadi gebrakan baru agar Arsitektur Melayu menjadi budaya turun-temurun yang tidak lekang oleh waktu.

\section{Kesimpulan}

Suku Melayu adalah salah satu suku asli penduduk Sumatera Utara yang memiliki karakeristik Arsitekur Melayu yang berbeda di setiap daerahnya, yang dapat dilihat pada bentuk bangunan, ornamen dan makna pada elemen bangunan Melayu. Ada beberapa kesultanan Melayu di Indonesia khususnya di pulau Sumatra dan Kalimantan, Sumatra Utara memiliki beberapa kesultanan Melayu yaitu kesultanan Deli, kesultanan Langkat dan lainya. Dengan adanya perbedaan antara kesultanan melayu di Sumatera Utara sehingga menghasilkan arsitektur Melayu yang berbeda-beda dan memiliki ciri khas tersendiri di masing-masing kesultanan tersebut.

Masuknya Islam ke daerah Sumatera banyak mempengaruhi arsitektur bangunan Melayu khusunya Masjid. Perubahan yang terjadi antara lain yaitu bentuk atap limas bertingkat menjadi kubah, serta penggunaan warna yang hijau-kuning yang dominan sebagai ciri khas melayu dan islam.

Dari kedua masjid yang diteliti, didapatkan beberapa persamaan dan perbedaan pada gaya arsitektur melayu-nya. Persamaaan dan perbedaannya dapat dilihat dari struktur dan bagian bangunan pada kedua masjid tersebut yang menjadi keunggulan serta kekuatan dari Arsitektur Melayu itu sendiri. Keunggulan yang ada merupakan potensi besar untuk mengangkat kembali eksistensi Arsitektur Melayu.

Dengan memasukkan unsur-unsur khas dari Arsitektur Melayu baik itu ornamen, warna ataupun bagian bangunan lainnya kedalam bangunan modern maka akan menjadi sebuah kekuatan dan berpotensi untuk memperkenalkannya kepada masyarakat awam yang belum mengetahui tentang Arsitektur Melayu. Bahkan tidak menutup kemungkinan untuk dapat meningkatkan eksistensi Arsitektur Melayu serta dapat menjadi gebrakan baru agar Arsitektur Melayu menjadi warisan budaya turun-temurun di Sumatera Utara yang tidak lekang oleh waktu.

\section{Referensi}

[1] Takari, Muhammad dkk. (2012) Sejarah Kesultanan Deli dan peradaban masyarakat. Medan: Universitas Sumatera Utara.

[2] Windari, Sri. (2017) Kesultanan Langkat di Sumatera Utara pada masa Sultan Abdul Azis (1827-1927 M). Medan: Jurnal UINSU

[3] Zalina, Atika. (2015) Studi Perbandingan Arsitektur Bangunan Masjid Al-Osmani dan Masjid Azizi Tanjung Pura. Medan: Universitas Sumatera Utara

[4] Rahmawati, Nur Syamsiyah. (2019) Kajian Perbandingan Gaya Arsitektur dan Pola Ruang Masjid Agung Surakarta dan Masjid Gedhe Kauman Yogyakarta. Surakarta: Univrsitas Muhammadiyah Surakarta

[5] Syarah, Yuni. (2017) Penggunaan Konsep Arsitektur Islam pada Bangunan Masjid Raya Lama Al-Osmani Medan. Medan: Universitas Sumatera Utara 